\title{
ANÁLISE COMPARATIVA DOS FATORES DE VIRULÊNCIA DOS ISOLADOS CLÍNICOS E AMBIENTAIS DE PSEUDOMONAS AERUGINOSA
}

\author{
Isabela Alves de Souza ${ }^{1}$, Doroti de Oliveira Garcia ${ }^{2}$, Laís Anversa ${ }^{3}$, Renata Katsuko Takayama Kobayashi ${ }^{3}$, \\ Gerson Nakazato ${ }^{3}$, Erika Kushikawa Saeki ${ }^{1}$ \\ ${ }^{1}$ Instituto Adolfo Lutz, Presidente Prudente, SP. ${ }^{2}$ Instituto Adolfo Lutz, Marilía, SP. ${ }^{3}$ Instituto Adolfo Lutz, Bauru, SP. \\ ${ }^{3}$ Universidade Estadual de Londrina - UEL, Londrina, PR. e-mail: erika.saeki@ial.sp.gov.br
}

\section{RESUMO}

Pseudomonas aeruginosa possui grande importância para a saúde pública por estar presente no ambiente e nas infecções clínicas. $O$ objetivo deste trabalho foi avaliar fenotipicamente os fatores de virulência motilidade, protease e ramnolipídeos em isolados clínicos e ambientais de $P$. aeruginosa. Vinte e cinco isolados clínicos e dez isolados ambientais foram analisados através de ensaios fenotípicos e categorizados em cepas não móveis, fracamente, moderadamente e altamente móveis; e produtores ou não de protease e ramnolipídeos. Em todos os ensaios, os isolados foram testados em triplicata em três dias diferentes. Os isolados ambientais produziram fatores de virulência como a motilidade (Swimming e Twitching) e Ramnolipídeos significativamente maior que os isolados clínicos. Este estudo nos alerta para o elevado nível de patogenicidade das cepas de $P$. aeruginosa, principalmente ambientais. A melhor compreensão da motilidade e produção de ramnolipídeos, fatores que estão diretamente associados à formação de biofilmes, pode favorecer estudos complementares às pesquisas visando o controle de bactérias patogênicas.

Palavras-chave: fatores de virulência, fibrose cística, infecções por Pseudomonas, patogenicidade.

\section{COMPARATIVE ANALYSIS OF THE VIRULENCE FACTORS IN PSEUDOMONAS AERUGINOSA STRAINS ISOLATED FROM CLINICAL AND ENVIRONMENTAL}

\begin{abstract}
Pseudomonas aeruginosa is a very important bacteria for public health because it is present in the environment and clinical infections. The aim of this study was to evaluate the virulence factors such as motility, protease and rhamnolipids in clinical and environmental $P$. aeruginosa isolates. Twenty-five clinical isolates and ten environmental isolates were analyzed by phenotypic assays and categorized into non-mobile, weakly, moderately and highly mobile strains; and producers of protease and rhamnolipids. The isolates were tested in triplicate on three different days. Environmental isolates produced virulence factors such as motility (Swimming and Twitching), and Ramnolipids significantly higher than clinical isolates. This study alerts us to the high level of pathogenicity of $P$. aeruginosa strains, mainly environmental strains. For a better understanding of motility and rhamnolipids, virulence factors that are directly associated with the biofilms formation, may favor studies that complement the research aimed at the control of pathogenic bacteria.
\end{abstract}

Keywords: virulence factors, cystic fibrosis, Pseudomonas infections, pathogenicity.

\section{INTRODUÇÃO}

A bactéria Pseudomonas aeruginosa é um bastonete Gram-negativo, aeróbio, porém capaz de sobreviver e se multiplicar lentamente em ambientes anaeróbios em determinadas situações ${ }^{1}$. Apresenta motilidade pela presença de um ou mais flagelos e, pode ser encontrado isolado ou em grupo ${ }^{2,3}$. Encontra-se amplamente distribuído, sendo um patógeno oportunista de fungos, helmintos, plantas, animais e humanos, com preferência por ambientes úmidos. Possui elevada resistência a antimicrobianos, grande 
diversidade genética e capacidade de formar biofilmes ${ }^{4-7}$.

Esta bactéria está frequentemente associada a infecções em pacientes imunocomprometidos, queimados, com fibrose cística, infecções gastrointestinais, do trato urinário e otites; mas também pode ser isolado em indivíduos saudáveis ${ }^{1,8}$.

$P$. aeruginosa tem representatividade em média de $75 \%$ de isolados de amostras clínicas ${ }^{9}$. Apesar de ser um agente de contaminação comumente encontrado em ambientes hospitalares, sua presença em ambientes aquáticos também é preocupante ${ }^{10}$, devido à sua capacidade de formação de biofilmes.

No Brasil, esta bactéria pode ser considerada uma boa indicadora de contaminação de águas de abastecimento ${ }^{2,10}$. Frequentemente isolada em águas superficiais como lagos e rios, possui preferência por águas residuárias devido à alta carga de nutrientes, porém pode sobreviver e se proliferar em ambientes com quantidades mínimas de nutrientes, como em água mineral ${ }^{1,2}$. Muitos estudos atribuem um papel importante da água a colonização em humanos por $P$. aeruginosa, principalmente quando associada à presença de bactérias contendo múltiplos fatores de virulência ${ }^{10}$.

Há uma intensa variabilidade de fatores de virulência em $P$. aeruginosa, oscilando de moderadamente a altamente virulentos, sendo seu potencial patogênico multifatorial, dependente da cepa, sítio de infecção, tanto em infecções adquiridas na comunidade como nas adquiridas em ambiente hospitalar ${ }^{3,9}$. Foi constatado que $P$. aeruginosa é capaz de acumular diferentes fatores de resistência e virulência, além de formar rotas de disseminação de genes relativos aos mesmos, dificultando o tratamento de infecções ${ }^{6,10}$.

Entre os fatores de virulência fundamentais para promover a patogenicidade da bactéria, destacam-se a motilidade, protease e ramnolipídeos ${ }^{3-6,9-12}$. A motilidade é dependente dos flagelos ou pili tipo IV, sendo importante para a proliferação bacteriana. As formas de movimentação mais comuns são Swarming, Swimming e Twitching ${ }^{5,12}$. A protease alcalina é secretada para auxiliar o patógeno durante a infecção $0^{3-6,9}$ e os ramnolipídeos estão envolvidos com o desenvolvimento de biofilmes, atividade antibacteriana e antifúngica e inibição da resposta fagocitária ${ }^{11}$.
Pseudomonas aeruginosa possui grande importância para a saúde pública, sendo classificada como prioridade 1 (crítico) dentre as três prioridades listadas pela Organização Mundial de Saúde na pesquisa de novos antimicrobianos $^{13}$. Contudo, trabalhos que correlacionem os fatores de virulência em isolados clínicos e ambientais ainda são raros. Assim, é observada a necessidade de conhecer o potencial patogênico dos isolados de $P$. aeruginosa tanto em áreas de assistência à saúde como no meio ambiente a fim de realizar uma comparação e formular mecanismos efetivos de vigilância e combate a sua disseminação.

O objetivo deste trabalho foi avaliar fenotipicamente os fatores de virulência como a motilidade, protease e ramnolipídeos em isolados clínicos e ambientais de Pseudomonas aeruginosa e comparar estatisticamente a prevalência dos fatores de virulência estudados por fonte de isolamento: clínica ou ambiental.

\section{METODOLOGIA}

Foram analisados vinte e cinco isolados clínicos oriundos de pacientes com fibrose cística e dez isolados ambientais de Pseudomonas aeruginosa obtidos de água de abastecimento público, provenientes do Núcleo de Coleção de Culturas do Instituto Adolfo Lutz e Centro de Laboratório Regional Instituto Adolfo Lutz de Bauru, respectivamente.

O estudo foi realizado nos Laboratórios de Microbiologia Alimentar e Bacteriologia do Centro de Laboratório Regional Instituto Adolfo Lutz de Presidente Prudente (SP) entre julho e novembro de 2018.

Este trabalho possui aprovação pelo Comitê Técnico Científico do Instituto Adolfo Lutz (CTC 31-J/2017).

Método em placa - motilidade Swarming

Os isolados testados foram inoculados em Caldo Luria Bertani (LB) e incubados a $37^{\circ} \mathrm{C}$ por $24 \mathrm{~h}$. Em seguida, inoculou-se $10 \mu \mathrm{L}$ de suspensão de $P$. aeruginosa no centro do Agar Swarming (glicose $1 \%$, peptona $0,5 \%$, extrato de levedura $0,2 \%$ e ágar 0,5\%), previamente mantidos em temperatura ambiente. A zona de motilidade foi medida após incubação a $30^{\circ} \mathrm{C}$ por $24 \mathrm{~h}$. $\mathrm{O}$ ensaio de motilidade foi realizado em triplicata em dias diferentes. As médias foram calculadas conforme Abdouchakour et al. ${ }^{14} \mathrm{e}$ classificadas em: não móvel ou fracamente 
móveis: $\mathrm{d}<20 \mathrm{~mm}$; moderadamente móveis: $20 \mathrm{~mm} \leq \mathrm{d}<40 \mathrm{~mm}$; e altamente móveis: $\mathrm{d} \geq 40 \mathrm{~mm}$.

Método em placa - motilidade Swimming

Os isolados foram semeados em Agar LB e incubados a $37^{\circ} \mathrm{C}$ por $24 \mathrm{~h}$. Foram inoculados em superfície do Agar Swimming (triptona 1\%, cloreto de sódio $0,5 \%$, ágar $0,3 \%$ ), previamente mantidos em temperatura ambiente. A área de motilidade foi medida após incubação a $30^{\circ} \mathrm{C}$ durante $24 \mathrm{~h}$. $O$ ensaio de motilidade foi realizado em triplicata em dias diferentes. As médias foram calculadas para a categorização conforme Abdouchakour et al. ${ }^{14} \mathrm{em}$ : não móvel ou fracamente móveis $\mathrm{d}<20 \mathrm{~mm}$, moderadamente móveis: $20 \mathrm{~mm} \leq \mathrm{d}<40 \mathrm{~mm}$; e altamente móveis: $\mathrm{d} \geq 40 \mathrm{~mm}$.

\section{Método em placa - motilidade Twitching}

Os isolados foram semeados em Agar LB e incubados a $37^{\circ} \mathrm{C}$ por $24 \mathrm{~h}$. Uma colônia de cada cepa foi perfurada em Agar Twitching (triptona $1 \%$, extrato de levedura $0,5 \%$, cloreto de sódio $1 \%$ e ágar $1 \%$ ) até o fundo da placa e incubada a $37^{\circ} \mathrm{C}$ por $24 \mathrm{~h}$. Posteriormente, o Agar foi cuidadosamente removido e a zona de motilidade foi medida em milímetros após coloração com violeta de cristal $2 \%$ por 2 h. 0 ensaio de motilidade foi realizado em triplicata em dias diferentes. As médias foram calculadas para a categorização conforme Wolska e Kot $^{15}$ em: não móveis: $\mathrm{d}<7 \mathrm{~mm}$; fracamente móveis: $d$ 7-15mm; moderadamente móveis: d 15-25mm; e altamente móveis: $\mathrm{d}>25 \mathrm{~mm}$.

\section{Método em placa - protease alcalina}

Os isolados foram inoculados em Caldo LB e incubados a $37^{\circ} \mathrm{C}$ por $24 \mathrm{~h}$. A atividade proteolítica foi confirmada pela formação de uma zona clara em torno do inoculo (10 $\mu \mathrm{L}$ em poço) em Agar Leite (leite em pó $1 \%$, peptona 0,1\%, cloreto de sódio $0,5 \%$, ágar $2 \%$ ) e quantificada através do diâmetro do halo após incubação a $37^{\circ} \mathrm{C}$ por $24 \mathrm{~h}$.

\section{Método em placa - ramnolipídeos \\ Inoculou-se a bactéria a ser testada em} Caldo LB e incubou-se a $37^{\circ} \mathrm{C}$ por $24 \mathrm{~h}$. A partir do crescimento de $P$. aeruginosa foi inoculado $10 \mu \mathrm{L}$ em poço na placa com Agar CTAB modificado, de acordo com Siegmund e Wagner ${ }^{16}$, e incubado a $37^{\circ} \mathrm{C}$ por $48 \mathrm{~h}$. A produção de ramnolipídios foi confirmada pela formação de um halo de coloração azul ao redor da colônia e o diâmetro do halo foi mensurado.

Análise dos dados

As variáveis foram comparadas utilizando o teste $T$ Student (dados com distribuição normal) ou teste de Mann-Whitney (dados com distribuição não normal). $O$ valor de $p<0,05$ foi considerado estatisticamente significativo. 0 Software $R$ (3.4.2) foi utilizado para representações gráficas e análise estatística.

\section{RESULTADOS}

Neste estudo foram analisados cinco fatores de virulência em $P$. aeruginosa: três de superfície (motilidades Swarming, Swimming e Twitching) e dois exoprodutos (Protease alcalina e Ramnolipídeos) em isolados clínicos e ambientais.

Os resultados da motilidade foram interpretados usando medidas de diâmetro em milímetros (Figura 1), seguida de categorização (Tabela 1), mostrando diversidade no comportamento de motilidade entre os grupos clínico e ambiental.

Conforme a Tabela 1, a motilidade Swarming dos isolados clínicos variou de $8 \mathrm{~mm}$ a $75 \mathrm{~mm}$, com média de $17 \pm 18 \mathrm{~mm}$. Quatro cepas foram classificadas como moderadamente móveis $(4 / 25 ; 16 \%)$ e duas como altamente móveis $(2 / 25 ; 8 \%)$. Entretanto, como a maior parte dos isolados apresentaram deslocamento menor que $20 \mathrm{~mm}$ na placa de Petri e foram consideradas não móveis $(19 / 25 ; 76 \%)$ (Tabela 2). As cepas ambientais variaram de 9 a $62 \mathrm{~mm}$ e média de $17 \pm 16 \mathrm{~mm}$ (Tabela 1). Uma cepa foi classificada como altamente móvel (1/10; 10\%), e o restante não móvel $(9 / 10 ; 90 \%)$ (Tabela 3$)$. Não houve diferença estatística significativa na motilidade Swarming entre os isolados clínicos e ambientais $(p=0,14)$ (Figura 2). 
A

B

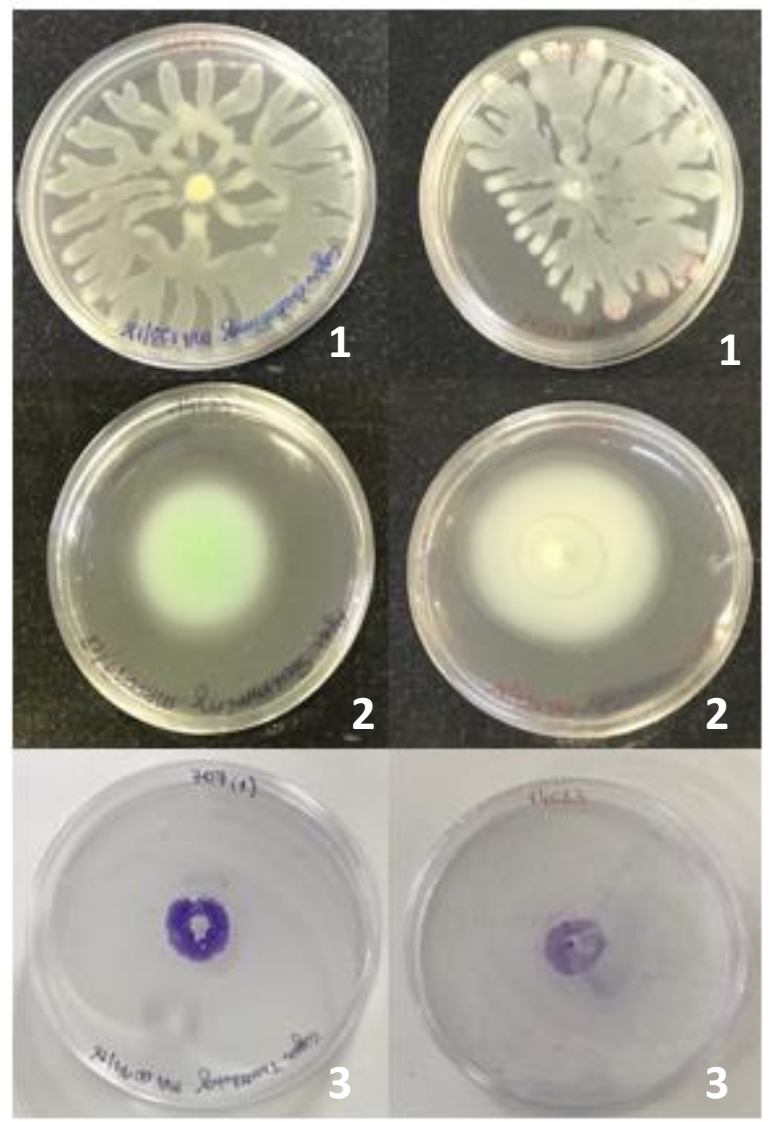

Figura 1. Ensaio fenotípico da motilidade. A1 - Swarming em isolado clínico, B1 - Swarming em isolado ambiental, A2 - Swimming em isolado clínico, B2 - Swimming em isolado ambiental, A3 - Twitching em isolado clínico, B3 - Twitching em isolado ambiental.

Tabela 1. Características dos isolados clínicos e ambientais de $P$. aeruginosa estudados: média e desvio padrão ( $\dot{x} \pm \mathrm{DP})$ e classificação das atividades $(\mathrm{mm})$ Swarming, Swimming, Twitching, Protease e Ramnolipídeos.

\begin{tabular}{|c|c|c|c|c|c|c|c|c|c|}
\hline Identificação & Origem & $\begin{array}{l}\text { Swarming } \\
\dot{\mathrm{x}} \pm \mathrm{DP}\end{array}$ & $\mathrm{C}^{1}$ & $\begin{array}{c}\text { Swimming } \\
\dot{\mathrm{X}} \pm \mathrm{DP}\end{array}$ & $C^{2}$ & $\begin{array}{l}\text { Twitching } \\
\dot{\mathbf{x}} \pm \text { DP }\end{array}$ & $C^{3}$ & $\begin{array}{l}\text { Protease } \\
\dot{\mathbf{x}} \pm \mathrm{DP}\end{array}$ & $\begin{array}{c}\text { Ramnolipídeos } \\
\dot{\mathbf{X}} \pm \text { DP }\end{array}$ \\
\hline IAL 6594 & Clínica & $9 \pm 2$ & NM & $10 \pm 2$ & NM & $8 \pm 2$ & FM & $19 \pm 2$ & $9 \pm 1$ \\
\hline IAL 6665 & Clínica & $9 \pm 1$ & NM & $17 \pm 2$ & NM & $9 \pm 1$ & FM & $12 \pm 5$ & $8 \pm 1$ \\
\hline IAL 6590 & Clínica & $12 \pm 2$ & NM & $23 \pm 3$ & MM & $11 \pm 2$ & FM & $18 \pm 2$ & $11 \pm 1$ \\
\hline IAL 6589 & Clínica & $11 \pm 1$ & NM & $14 \pm 2$ & NM & $10 \pm 1$ & FM & $22 \pm 1$ & $11 \pm 1$ \\
\hline IAL 6592 & Clínica & $9 \pm 1$ & NM & $10 \pm 1$ & NM & $3 \pm 2$ & NM & $15 \pm 1$ & 0 \\
\hline IAL 6591 & Clínica & $11 \pm 2$ & NM & 0 & NM & $6 \pm 1$ & NM & 0 & 0 \\
\hline IAL 6574 & Clínica & $8 \pm 1$ & NM & $17 \pm 3$ & NM & $7 \pm 2$ & FM & 0 & 0 \\
\hline IAL 6584 & Clínica & $9 \pm 1$ & NM & $11 \pm 3$ & NM & $9 \pm 2$ & FM & $21 \pm 4$ & 0 \\
\hline IAL 6598 & Clínica & $10 \pm 2$ & NM & $10 \pm 1$ & NM & $10 \pm 1$ & FM & $10 \pm 1$ & 0 \\
\hline IAL 6600 & Clínica & $9 \pm 1$ & NM & 0 & NM & $7 \pm 1$ & FM & $11 \pm 1$ & 0 \\
\hline IAL 6601 & Clínica & $10 \pm 2$ & NM & 0 & NM & $13 \pm 2$ & $\mathrm{FM}$ & $19 \pm 2$ & 0 \\
\hline IAL 6577 & Clínica & $12 \pm 3$ & NM & $20 \pm 3$ & MM & $8 \pm 1$ & FM & $18 \pm 2$ & $14 \pm 2$ \\
\hline IAL 6688 & Clínica & $13 \pm 2$ & NM & $27 \pm 1$ & MM & $18 \pm 1$ & MM & $21 \pm 2$ & $12 \pm 1$ \\
\hline IAL 6582 & Clínica & $21 \pm 3$ & MM & $36 \pm 2$ & MM & $13 \pm 1$ & $\mathrm{FM}$ & $21 \pm 2$ & $14 \pm 1$ \\
\hline IAL 6596 & Clínica & $21 \pm 3$ & MM & $44 \pm 3$ & $\mathrm{AM}$ & $18 \pm 1$ & MM & $31 \pm 3$ & $16 \pm 1$ \\
\hline IAL 6603 & Clínica & $9 \pm 1$ & NM & $13 \pm 2$ & NM & $8 \pm 1$ & $\mathrm{FM}$ & $9 \pm 2$ & 0 \\
\hline IAL 6575 & Clínica & 8 & NM & 0 & NM & $10 \pm 1$ & FM & $18 \pm 2$ & $12 \pm 1$ \\
\hline IAL 6576 & Clínica & $9 \pm 1$ & NM & $39 \pm 4$ & MM & $5 \pm 2$ & NM & $15 \pm 1$ & $8 \pm 2$ \\
\hline
\end{tabular}




\begin{tabular}{|c|c|c|c|c|c|c|c|c|c|}
\hline IAL 6587 & Clínica & $74 \pm 7$ & AM & $26 \pm 6$ & $\mathrm{MM}$ & $7 \pm 2$ & $\mathrm{FM}$ & $23 \pm 3$ & $15 \pm 1$ \\
\hline IAL 6580 & Clínica & $75 \pm 5$ & AM & $29 \pm 4$ & MM & $6 \pm 2$ & NM & $21 \pm 2$ & $15 \pm 1$ \\
\hline IAL 6573 & Clínica & $11 \pm 3$ & NM & $43 \pm 2$ & AM & $6 \pm 1$ & NM & $21 \pm 1$ & $15 \pm 1$ \\
\hline IAL 6581 & Clínica & $29 \pm 2$ & MM & $25 \pm 3$ & $\mathrm{MM}$ & $6 \pm 1$ & NM & $21 \pm 1$ & $16 \pm 1$ \\
\hline $762(1)$ & Clínica & $8 \pm 1$ & NM & $32 \pm 3$ & MM & $5 \pm 1$ & NM & 0 & 0 \\
\hline IAL 6578 & Clínica & $22 \pm 4$ & MM & $48 \pm 2$ & AM & $6 \pm 1$ & NM & $21 \pm 1$ & $15 \pm 1$ \\
\hline IAL 6579 & Clínica & $11 \pm 2$ & NM & $30 \pm 3$ & $\mathrm{MM}$ & $13 \pm 1$ & $\mathrm{FM}$ & $20 \pm 1$ & $13 \pm 1$ \\
\hline 04023 & Ambiental & $14 \pm 3$ & NM & $45 \pm 2$ & AM & $15 \pm 1$ & FM & $18 \pm 2$ & $15 \pm 1$ \\
\hline 14048 & Ambiental & $11 \pm 2$ & NM & $40 \pm 2$ & AM & $14 \pm 2$ & FM & $22 \pm 2$ & 16 \\
\hline 14083 & Ambiental & $12 \pm 2$ & NM & $45 \pm 3$ & AM & $17 \pm 2$ & $\mathrm{MM}$ & $22 \pm 1$ & $14 \pm 2$ \\
\hline 04015 & Ambiental & $62 \pm 4$ & AM & $52 \pm 3$ & AM & $10 \pm 1$ & $\mathrm{FM}$ & $16 \pm 3$ & $14 \pm 1$ \\
\hline 04021 & Ambiental & 9 & NM & $44 \pm 4$ & AM & $14 \pm 1$ & $\mathrm{FM}$ & $12 \pm 1$ & $15 \pm 1$ \\
\hline 35010 & Ambiental & $14 \pm 1$ & NM & $22 \pm 3$ & MM & $13 \pm 1$ & $\mathrm{FM}$ & $18 \pm 1$ & 0 \\
\hline 04064 & Ambiental & $12 \pm 4$ & NM & $44 \pm 3$ & AM & $16 \pm 1$ & MM & $19 \pm 3$ & $17 \pm 1$ \\
\hline 04024 & Ambiental & $11 \pm 1$ & NM & $36 \pm 2$ & $\mathrm{MM}$ & $15 \pm 1$ & $\mathrm{FM}$ & $14 \pm 2$ & $15 \pm 1$ \\
\hline 14063 & Ambiental & $13 \pm 2$ & NM & $25 \pm 2$ & $\mathrm{MM}$ & $10 \pm 1$ & FM & $13 \pm 1$ & $12 \pm 2$ \\
\hline 04010 & Ambiental & $12 \pm 2$ & NM & $46 \pm 2$ & AM & $17 \pm 1$ & MM & $18 \pm 1$ & $15 \pm 2$ \\
\hline
\end{tabular}

Tabela 2. Porcentagem (\%) das atividades $(\mathrm{mm})$ das motilidades Swarming, Swimming e Twitching em isolados clínicos.

\begin{tabular}{ccccc}
\hline Tipo de & \multicolumn{4}{c}{ Classificação } \\
\cline { 2 - 5 } motilidade & não móvel & fracamente & moderado & muito móvel \\
\hline Swarming & $19(76 \%)$ & - & $4(16 \%)$ & $2(8 \%)$ \\
Swimming & $12(48 \%)$ & - & $10(40 \%)$ & $3(12 \%)$ \\
Twitching & $8(32 \%)$ & $15(60 \%)$ & $2(8 \%)$ & 0 \\
\hline
\end{tabular}

Tabela 3. Porcentagem (\%) das atividades $(\mathrm{mm})$ das motilidades Swarming, Swimming e Twitching em isolados ambientais.

\begin{tabular}{ccccc}
\hline Tipo de & \multicolumn{4}{c}{ Classificação } \\
\cline { 2 - 5 } motilidade & não móvel & fracamente & moderado & muito móvel \\
\hline Swarming & $9(90 \%)$ & - & 0 & $1(10 \%)$ \\
Swimming & 0 & - & $3(30 \%)$ & $7(70 \%)$ \\
Twitching & 0 & $8(80 \%)$ & $2(20 \%)$ & 0 \\
\hline
\end{tabular}

A maior parte dos isolados clínicos apresentou-se não móvel/fracamente móvel para motilidade Swimming (12/25; 48\%) (Tabela 2). Nos isolados ambientais, todos apresentaram motilidade Swimming de 22 a $52 \mathrm{~mm}$ com média de $40 \pm 10 \mathrm{~mm}$, a maioria classificada como altamente móvel $(7 / 10 ; 70 \%)$, o restante $(3 / 10$; $30 \%)$ moderadamente móvel (Tabela 3). Houve diferença estatística significativa quanto à motilidade Swimming nos dois grupos estudados $(p<0,05)$ (Figura 2).
A atividade da motilidade Twitching dos 25 isolados clínicos de $P$. aeruginosa variou de 3 a $18 \mathrm{~mm}$ com média de $9 \pm 4 \mathrm{~mm}$ (Tabela 1 ). A maior parte das cepas clínicas apresentou-se fracamente móvel $(15 / 25 ; 60 \%)$ (Tabela 2). Os 10 isolados ambientais variaram de 10 a $17 \mathrm{~mm}$ e média de $14 \pm 2 \mathrm{~mm}$, onde a maior parte das cepas ambientais também se apresentou fracamente móvel $(8 / 10 ; 80 \%)$ (Tabela 3). De acordo com a Figura 2, os isolados ambientais produziram significativamente maior motilidade Twitching do que os isolados clínicos $(p<0,05)$. 


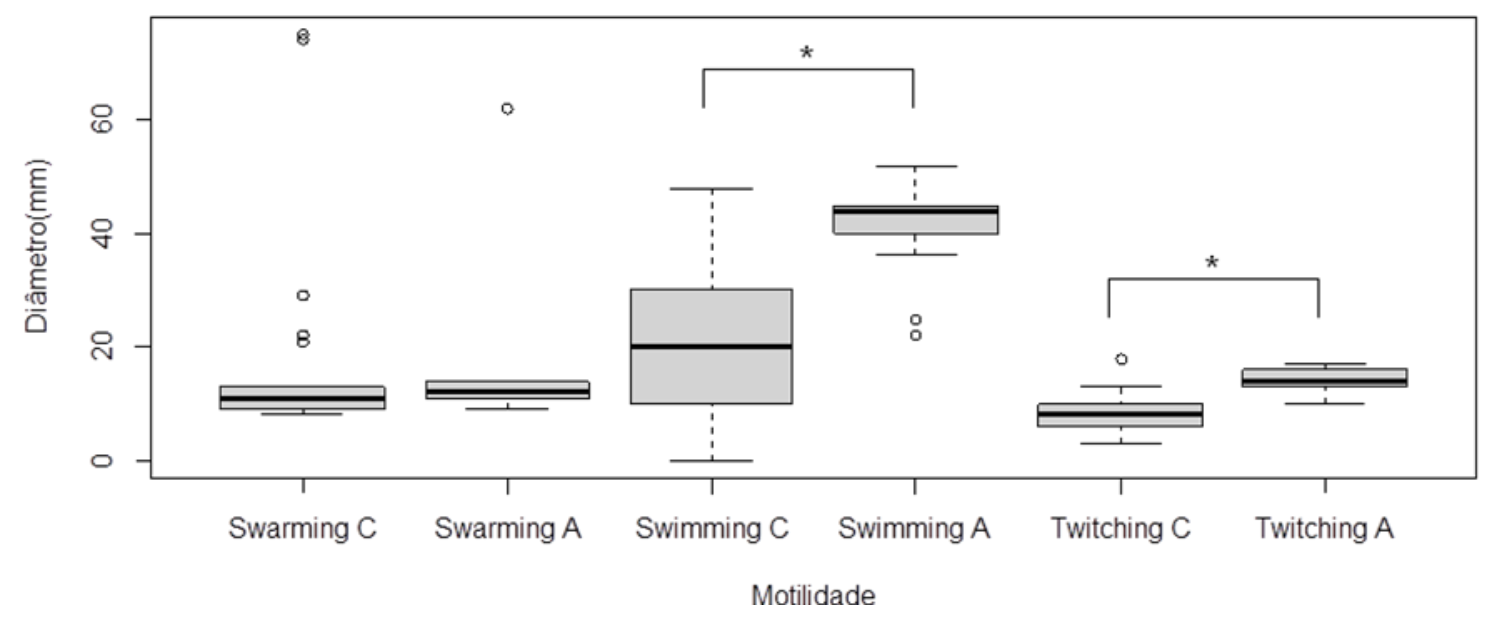

Figura 2. Gráfico Boxplot dos resultados de motilidade Swarming, Swimming e Twitching dos isolados clínicos e ambientais. As diferenças significativas estão indicadas com ${ }^{*}(p<0,05)$. C: isolados clínicos; A: isolados ambientais.

Neste estudo, $12 \%(3 / 25)$ das cepas clínicas e $10 \%(1 / 10)$ das cepas ambientais apresentaram as duas motilidades Twitching e Swarming.

Quanto à produção de protease alcalina, houve produção em 22 dos 25 isolados clínicos avaliados (88\%), obtendo média de $16 \pm 8 \mathrm{~mm}$ (Tabela 1). Entre os isolados ambientais houve síntese de protease alcalina em todos os isolados analisados, apresentando média de $17 \pm 3 \mathrm{~mm}$. Não houve diferença estatística significativa na atividade proteolítica comparando-se os isolados clínicos e ambientais $(p=0,84)$ (Figura 3 ).

A respeito dos ramnolipídeos, houve síntese em 16 dos 25 isolados clínicos avaliados (64\%), apresentando média de $8 \pm 7 \mathrm{~mm}$ (Tabela 1). Entre as cepas ambientais, 9 das 10 pesquisadas produziram ramnolipídeos (90\%) e média de $13 \pm 5 \mathrm{~mm}$. Houve diferença estatística significativa na síntese de ramnolipídeos nos dois grupos estudados $(p<0,05)$ (Figura 3$)$.

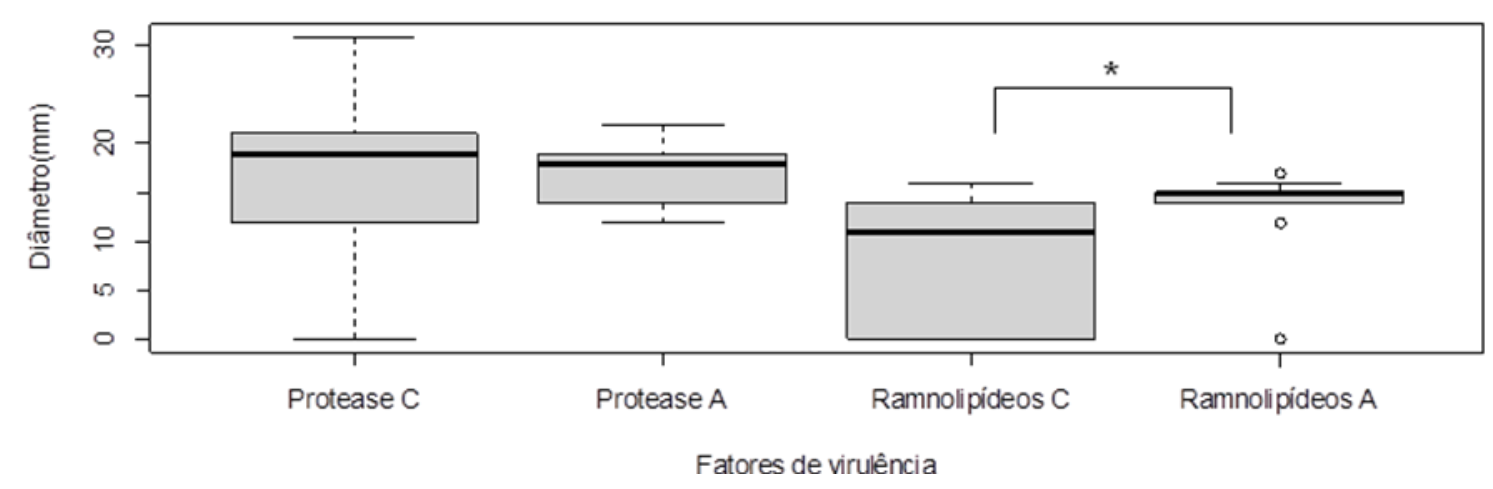

Figura 3. Gráfico Boxplot dos resultados de Protease e Ramnolipídeos dos isolados clínicos e ambientais. As diferenças significativas estão indicadas com ${ }^{*}(p<0,05)$. C: isolados clínicos; A: isolados ambientais. 


\section{DISCUSSÃO}

Encontra-se bem documentado a importância da bactéria Pseudomonas aeruginosa para a saúde pública, por sua capacidade infecciosa, colonização de diversas superfícies bióticas e abióticas e crescente resistência antimicrobiana, tornando-se essencial entender sua patogênese. Alguns estudos têm associado os isolados obtidos do ambiente, principalmente de água encanada, com cepas infecciosas ${ }^{10,14,17-18}$.

Grande parte das cepas de $P$. aeruginosa produzem fatores de virulência que atuam na superfície (que permite fixação bacteriana, colonização e invasão) associada a outros fatores de virulência como hemolisina, elastase, protease. A combinação destes fatores é determinante para o estabelecimento de uma infecção ${ }^{19}$.

Entre os tipos de motilidade bacteriana, Macin et al. ${ }^{20}$ observaram que a motilidade Swarming de isolados de $P$. aeruginosa obtidos de pacientes com fibrose cística foi de $84 \%$, um resultado menor do que a detectada em pacientes sem a doença (97\%), com indicação que a pressão contínua e seletiva no ambiente pode levar a algumas mudanças fenotípicas nas bactérias para ajudar a sua adaptação ao hospedeiro, não necessariamente permanentemente ligado as suas estruturas móveis (flagelo e pili tipo IV).

Entre as cepas ambientais, a ausência de motilidade Swarming também foi predominante, entretanto outros estudos encontraram a maioria dos isolados ambientais com motilidade Swarming moderada ou alta, variando de 25 a 80 $\mathrm{mm}^{14,18}$

Os dois grupos, clínico e ambiental, demonstraram habilidades semelhantes para exibir a motilidade Swarming, que é mediada pelos flagelos em colaboração com os pili do tipo IV. Apesar de a motilidade ser necessária no desenvolvimento do biofilme, isolados que exibem pouca ou nenhuma motilidade Swarming são mais propensos a terem sucesso em sua formação, pois se fixam mais eficientemente em sua estrutura que compõe o biofilme ${ }^{11}$.

Quanto à motilidade Swimming, os isolados ambientais deste estudo se destacaram, pois apresentaram diâmetros maiores que isolados ambientais encontrados em outros autores $^{10,14}$.

Para motilidade Twitching, houve divergência de nosso estudo com outros publicados, tanto entre as cepas clínicas como nas ambientais, os dois grupos demonstrando moderada e alta atividade na literatura ${ }^{10}$.

A fraca motilidade dos isolados clínicos pode ser explicada pela correlação entre a atividade da motilidade Twitching, a formação de biofilmes e a fonte de isolamento das cepas ${ }^{15}$, já que cepas não móveis, como as de pacientes com fibrose cística, são dificilmente fagocitadas, despistando o sistema imune. Apesar de esta estratégia afetar a capacidade em causar infecções, favorece a persistência no hospedeiro $^{20}$.

É estabelecido que cada um dos três sistemas de motilidade funciona de forma independente e parece não estar relacionado com outros caracteres bacterianos, apesar de ser importante ressaltar que a motilidade Swarming não depende exclusivamente do pili IV, mas também do flagelo ${ }^{14,18}$.

A alta motilidade Twitching, por exemplo, leva à redução da formação de biofilme por $P$. aeruginosa, enquanto a motilidade Swarming é necessária para o desenvolvimento de suas estruturas, mas dispensável em sua permanência no hospedeiro. Isto é, a bactéria adapta sua atividade móvel conforme a sua necessidade no hospedeiro, seja para estabelecer a infeç̧ão, formar biofilme ou garantir sua permanência no organismo, independentemente de sua origem, clínica ou ambiental, o que pode explicar a falta de diferenças significativas em algumas características adaptativas, como formação de biofilme, motilidade e resistência ${ }^{14,21}$.

Quanto à protease alcalina, assim como neste estudo, outros estudos apresenta atividade proteolítica nos isolados clínicos e ambientais ${ }^{9,20,22}$. A protease alcalina exerce um papel importante na virulência durante a colonização, contribuindo para o desmoronamento das barreiras físicas do hospedeiro e aumentando a proliferação bacteriana, fornecendo aminoácidos e peptídeos das proteínas teciduais às bactérias. Em estágios mais avançados, pode interferir com o mecanismo de defesa imune por degradar imunoglobulinas ${ }^{23}$.

A atuação de surfactantes, como os ramnolipídeos, é relatada como agente indutor de expansão da motilidade Swarming ${ }^{24}$. No presente estudo esta relação foi concordante nos isolados clínicos, já que as cepas que não produzem ramnolipídeos apresentaram 
motilidade Swarming sem atividade. Os isolados ambientais apresentaram fenótipos de Swarming e ramnolipídeos diversos, sem associação considerável entre si.

Os ramnolipídeos estão envolvidos na formação de biofilmes. Eles são responsáveis por induzirem a liberação de lipopolissacarídeos, aumentando a hidrofobicidade da superfície celular, sendo um regulador ambiental quando ocorrem mudanças nas condições nutricionais e favorecem a adesão primária de células planctônicas. Funciona também como um "escudo" contra células polimorfonucleadas, contribuindo para a fixação da bactéria no hospedeiro ${ }^{11}$.

$P$. aeruginosa possui preferência por ambientes úmidos, portanto deve-se dar atenção especial à pias, banheiras e chuveiros ${ }^{7}$. Sua ocorrência em águas de abastecimento indica deficiência no controle da rede de distribuição de água e pode ser indicativo de disseminação de microrganismos de origem nosocomial no ambiente aquático ${ }^{25}$, ocasionando em fonte possível de infecção por $P$. aeruginosa, principalmente em ambientes onde circulam pessoas imunocomprometidas, como hospitais ${ }^{15}$.

Conclui-se que as análises fenotípicas realizadas revelaram grande variabilidade dos fatores de virulência entre os isolados estudados, o que nos alerta para o elevado nível de patogenicidade das cepas, principalmente as ambientais.

Os isolados presentes no ambiente, como em águas de abastecimento público, pode oferecer risco patogênico, principalmente para os imunocomprometidos, já que apresentaram fatores de virulência importantes como motilidade (Swimming e Twitching) e ramnolipídeos com resultados muitas vezes maiores que os isolados clínicos. A produção exacerbada destes fenótipos representa um potencial de colonização e infeç̧ão no hospedeiro, garantindo a rápida disseminação $\mathrm{e}$ capacidade inflamatória.

Por isso, o estudo da produção de protease, ramnolipídeos e motilidade em Pseudomonas aeruginosa é de extrema importância para a compreensão dos fatores de virulência e seus mecanismos envolvidos em sua patogenicidade. Os tipos de motilidades identificados, fatores que estão diretamente associados à formação de biofilmes podem ser responsáveis por estudos complementares às pesquisas visando o controle de bactérias patogênicas.

\section{AGRADECIMENTOS}

As pesquisadoras Dra. Doroti de Oliveira Garcia do Centro de Laboratório Regional (CLR) Instituto Adolfo Lutz de Marília e a Me. Laís Anversa do CLR Instituto Adolfo Lutz de Bauru por terem gentilmente cedido os isolados utilizados neste trabalho $\mathrm{e}$ a todos os profissionais do Laboratório do Núcleo de Ciências Químicas e Bromatológicas do CLR Instituto Adolfo Lutz de Presidente Prudente pelo apoio e auxílio na execução do mesmo.

\section{CONFLITO DE INTERESSES}

As autoras declaram não haver qualquer potencial conflito de interesse que possa interferir na imparcialidade deste trabalho científico.

\section{REFERÊNCIAS}

1. Arruda KLS. Resistência das Pseudomonas à Ciprofloxacina e sua relação com a saúde ambiental. [Monografia] Florianópolis: Universidade Federal de Santa Catarina, 2013.

2. Dos Santos G, Colombo TE. Prevalência de Pseudomonas aeruginosa em águas e superfície. J Health Sci Instit. 2015;33(4):314-8.

3. Tana FL. Avaliação da expressão e do papel dos microRNAs mmu-miR-155-5p e mmu-miR-146b$5 p$ durante a infecção pulmonar causada pela bactéria Pseudomonas aeruginosa. [Dissertação] Alfenas: Universidade Federal de Alfenas, 2017.

4. Brooks GF, Carroll KC, Butel JS, Morse SA, Mietzner TA. Microbiologia Médica de Jawetz, Melnick \& Adelberg. 26.ed. Porto Alegre: AMGH; 2014.

5. Burrows LL. Pseudomonas aeruginosa twitching motility: type IV pili in action. Ann Rev Microbiol. 2012;66:493-520. DOI: https://dx.doi.org/10.1146/annurev-micro$\underline{092611-150055}$

6. Jácome PRLA, Alves LR, Cabral AB, Lopes ACS, Maciel MAV. Phenotypic and molecular characterization of antimicrobial resistance and virulence factors in Pseudomonas aeruginosa clinical isolates from Recife, state of Pernambuco, Brazil. Rev Soc Bras Med Trop. 2012;45(6):707- 
12. DOI: https://dx.doi.org/10.1590/S0037$\underline{86822012000600010}$

7. Bernardi PM. Avaliação por microdiálise da penetração pulmonar da Tobramicina em modelo de pneumonia por microrganismo formador de biofilme. [Dissertação] Porto Alegre: Universidade Federal do Rio Grande do Sul, 2016.

8. Pariguana REC, Montoya RC. Bacteriocinas producidas por Pseudomonas aeruginosa y su acción inhibitoria frente a Helicobacter pylori. [Monografia] Cusco: Universidad Nacional de San Antonio Abad Del Cusco, 2012.

9. Silva ST. Análise fenotípica e genética de fatores de virulência de isolados clínicos de Pseudomonas aeruginosa multidroga-sensível e multidroga-resistente de Recife - PE. [Dissertação] Recife: Universidade Federal de Pernambuco, 2016.

10. Magalhães MJTL. Caracterização fenotípica e similaridade genética de Pseudomonas aeruginosa provenientes de efluentes hospitalares e água superficial do igarapé do Mindu/Manaus - AM. [Dissertação] Manaus: Universidade Federal do Amazonas, 2013.

11. Abdel-Mawgoud AM, Lépine $F$, Déziel $E$. Rhamnolipids: diversity of structures, microbial origins and roles. Appl microbiol Biotechnol. 2010;86(5):1323-36.

DOI: https://dx.doi.org/10.1007/s00253-010-2498-2

12. Al-Haidari RA, Shaaban MI, Ibrahim SRM, Mohamed GA. Anti-quorum sensing activity of some medicinal plants. African J Traditional, Complem Altern Med. 2016;13(5):67-71. DOI: https://dx.doi.org/10.21010/ajtcam.v13i5.10

13. World Health Organization. Global priority list of antibiotic-resistant bacteria to guide research, discovery, and development of new antibiotics. Geneva: World Health Organization, 2017.

14. Abdouchakour F, Aujoulat F, Licznar-Fajardo $P$, Marchandin $H$, Toubiana $M$, Parer $S$ et al. Intraclonal variations of resistance and phenotype in Pseudomonas aeruginosa epidemic high-risk clone ST308: A key to success within a hospital? Int J Med Microbiol. 2018;308(2):27989. DOI: https://dx.doi.org/10.1016/i.ijmm.2017.11.008
15. Wolska K, Kot B. Twitching motility activity, biofilm formation, and genetic typing for clinical isolates of Pseudomonas aeruginosa by random amplified DNA PCR. Acta Microbiol immunol Hungarica. $\quad 2013 ; 60(3): 313-28 . \quad$ DOI: https://dx.doi.org/10.1556/AMicr.60.2013.3.7

16. Siegmund I, Wagner F. New method for detecting rhamnolipids excreted by Pseudomonas species during growth on mineral agar. Biotechnol Lett. 1991;5(4):265-8.

17. Chaves MA. Perfil de suscetibilidade em bastonetes gram negativos não fermentadores isolados de amostra de água superficial submetida a tratamento com antimicrobiano. [Dissertação] Porto Alegre: Universidade Federal do Rio Grande do Sul, 2017.

18. Otton LM, Silva Campos M, Meneghetti KL, Corção $G$. Influence of twitching and swarming motilities on biofilm formation in Pseudomonas strains. Arch Microbiol. 2017;199(5):677-82. DOI: https://dx.doi.org/10.1007/s00203-017-1344-7

19. Santos SO. Estudo de isolados clínicos de Pseudomonas aeruginosa e Acinectobacter spp. multiresistentes do Hospital Universitário de Santa Maria. [Dissertação] Santa Maria: Universidade Federal de Santa Maria, 2014.

20. Macin S, Akarca M, Sener B, Akyon Y. Comparison of virulence factors and antibiotic resistance of Pseudomonas aeruginosa strains isolated from patients with and without cystic fibrosis. Rev Romana Med Laborator. 2017;25(4):327-34. DOI: https://dx.doi.org/10.1515/rrlm-2017-0027

21. Wu H, Lee B, Yang L, Wang H, Givskov $M$, Molin S et al. Effects of ginseng on Pseudomonas aeruginosa motility and biofilm formation. FEMS Immunol Med Microbiol. 2011;62(1):49-56. DOI: https://dx.doi.org/10.1111/j.1574695X.2011.00787

22. Ciragil P, Soyletir G. Alginate, elastase and alkaline protease production of Pseudomonas aeruginosa strains isolated from various body sites. Mikrobiyoloji Bulteni. 2004;38(4):341-7.

23. Stehling EG. Estudo comparativo dos fatores de virulência de Pseudomonas aeruginosa isoladas de fibrose cística e outras infecções. 
[Dissertação] Campinas: Universidade Estadual de Campinas, 1999.

24. Kearns DB. A field guide to bacterial swarming motility. Nature Rev Microbiol. 2010;8(9):634. DOI: https://dx.doi.org/10.1038/nrmicro2405

25. Peresi JTM, Almeida IAZC, Teixeira ISC, Silva SIL, Alves EC, Marques DF et al. Pseudomonas aeruginosa: ocorrência e suscetibilidade aos agentes antimicrobianos de isolados de amostras de água tratada utilizada em solução de diálise. Rev Inst Adolfo Lutz. 2011;70(4):542-7. 